\title{
A systematic review of sexual and reproductive health interventions for young people in humanitarian and lower-and- middle-income country settings
}

\author{
Alethea Desrosiers ${ }^{1}$, Theresa Betancourt ${ }^{1}$, Yasmine Kergoat ${ }^{2}$, Chiara Servilli ${ }^{2}$, Lale Say ${ }^{2}$ and Loulou Kobeissi ${ }^{2^{*}}$ (D)
}

\begin{abstract}
Background: Accessibility of sexual and reproductive health (SRH) services in many lower-and-middle-income countries (LMICS) and humanitarian settings remains limited, particularly for young people. Young people facing humanitarian crises are also at higher risk for mental health problems, which can further exacerbate poor SRH outcomes. This review aimed to explore, describe and evaluate SRH interventions for young people in LMIC and humanitarian settings to better understand both SRH and psychosocial components of interventions that demonstrate effectiveness for improving SRH outcomes.
\end{abstract}

Methods: We conducted a systematic review of studies examining interventions to improve SRH in young people in LMIC and humanitarian settings following Preferred Reporting Items for Systematic Reviews and Meta-analysis (PRISMA) standards for systematic reviews. Peer-reviewed journals and grey literature from January 1, 2000 to December 31, 2018 were included. Two authors performed title, abstract and full-text screening independently. Data was extracted and analyzed using a narrative synthesis approach and the practice-wise clinical coding system.

Results: The search yielded 813 results, of which 55 met inclusion criteria for full-text screening and thematic analysis. Primary SRH outcomes of effective interventions included: contraception and condom use skills, HIV/STI prevention/education, SRH knowledge/education, gender-based violence education and sexual self-efficacy. Common psychosocial intervention components included: assertiveness training, communication skills, and problem-solving.

Conclusions: Findings suggest that several evidence-based SRH interventions may be effective for young people in humanitarian and LMIC settings. Studies that use double blind designs, include fidelity monitoring, and focus on implementation and sustainability are needed to further contribute to this evidence-base.

Keywords: Sexual health, Reproductive health, Young people, Humanitarian settings

\footnotetext{
* Correspondence: kobeissil@who.int

${ }^{2}$ Department of Sexual and Reproductive Health Research, World Health

Organization, 20 Avenue Appia, 1211 Geneva 27, Switzerland

Full list of author information is available at the end of the article
}

(c) The Author(s). 2020 Open Access This article is licensed under a Creative Commons Attribution 4.0 International License, which permits use, sharing, adaptation, distribution and reproduction in any medium or format, as long as you give appropriate credit to the original author(s) and the source, provide a link to the Creative Commons licence, and indicate if changes were made. The images or other third party material in this article are included in the article's Creative Commons licence, unless indicated otherwise in a credit line to the material. If material is not included in the article's Creative Commons licence and your intended use is not permitted by statutory regulation or exceeds the permitted use, you will need to obtain permission directly from the copyright holder. To view a copy of this licence, visit http://creativecommons.org/licenses/by/4.0/ The Creative Commons Public Domain Dedication waiver (http://creativecommons.org/publicdomain/zero/1.0/) applies to the data made available in this article, unless otherwise stated in a credit line to the data. 


\section{Background}

Sexual and reproductive health (SRH) and access to sexual and reproductive health services are basic human rights. Based on the sustainable development goals (target 3.7), universal access to sexual and reproductive health services should be attained by 2030. However $\mathrm{SRH}$ knowledge and service use remain limited in many lower-and-middle-income countries (LMICs) as well as in fragile settings such as humanitarian emergencies. It is estimated that nearly two billion people worldwide live in areas affected by conflict and violence, and the number of forcibly displaced people is at its highest record to date, at over 68.5 million people worldwide [1]. Of those people in need of humanitarian assistance, an estimated 34 million are adolescent girls and women of reproductive age $[2,3]$. LMICs and regions experiencing humanitarian emergencies typically have limited resources and infrastructure to support sexual and reproductive health services, resulting in poor SRH outcomes and limited SRH service utilization [4-6]. The minimal initial services package (MISP) was developed to respond to reproductive health needs at the onset of crisis and includes the following six objectives: identifying an organization to lead MISP implementation, preventing sexual violence and responding to the needs of survivors, preventing the transmission of ad reducing morbidity and mortality due to human immunodeficiency virus (HIV) and other STIs, preventing excess maternal and newborn morbidity and mortality, preventing unintended pregnancies and planning to integrate comprehensive SRH services into primary health care. Despite efforts to improve the availability and uptake of the (MISP), unmet SRH needs remain high and are particularly dire for young people affected by humanitarian emergencies [4]. There is also a substantial lack of research investigating effectiveness and scale-up of interventions focused on improving SRH outcomes among young people in specific cultural contexts [7, 8]. Further research is needed to better understand which SRH interventions have demonstrated effectiveness for improving SRH outcomes in LMIC and humanitarian settings in order to increase evidence-based practices and inform decisions to invest in scaling-up of effective intervention packages.

Poor sexual and reproductive health affects both young men and women, but it is particularly problematic among young women and girls in LMIC and humanitarian settings $[9,10]$. Research suggests that humanitarian crises can further compound the risks associated with poor SRH and limited service availability for young women in these contexts $[11,12]$. Inadequate SRH service provision has been linked with unintended pregnancies, complications related to unsafe abortions, genderbased violence, and increases in HIV and sexually transmitted infections (STIs) [13]. It is estimated that each year, 12 million adolescent girls and women give birth, and 3.2 million have an unsafe abortion in humanitarian settings [14]. Further, pregnancy during adolescence has been associated with numerous adverse outcomes, including social, economic, and health problems for both young mothers and their children $[9,14]$. Access and use of SRH services among young women in LMIC and humanitarian settings is limited, even when services are available $[13,15]$. Despite having minimum standards to guide service provision, access to family planning, SRH interventions, antenatal care, and services for sexual violence all remain low $[2,5,16]$.

Further, for young people in humanitarian and LMIC settings, comorbid mental health disorders can further compound the risks for poor SRH outcomes and respectively impact SRH service use. Mental health disorders account for approximately 16\% of the global burden of disease among young people aged 10-19 [17]. Young people living in humanitarian and fragile settings, including refugees and displaced persons, are at an even higher risk of developing mental health problems due to their living conditions $[17,18]$. These risks are further heightened among young women and girls because they are more likely to develop mental health problems (e.g., depression, anxiety, psychological distress) and to experience sexual violence in comparison with men and boys [19, 20]. The high prevalence of mental health problems among young people in humanitarian emergencies is especially concerning because mental health problems have been associated with greater levels of risky sexual behaviors, such as inconsistent contraceptive use, which increases the likelihood of unwanted pregnancies and unsafe abortions as well as the likelihood of contracting HIV and other STIs [21]. Preliminary evidence supports the notion that SRH interventions for people with mental health disorders can reduce sexual risk taking [22]. Integrating psychosocial components that address mental health challenges into SRH intervention packages could therefore enhance overall intervention outcomes; however, the evidence base evaluating the effectiveness of integrated SRH packages in humanitarian emergencies is virtually absent.

Improving SRH outcomes and services among young people in LMIC and humanitarian settings is of critical importance for global public health. With this in mind, this systematic review aims to explore, describe and evaluate more rigorously tested SRH interventions for young people in LMIC and humanitarian settings to better inform the evidence-base on interventions that demonstrate effectiveness for improving SRH outcomes. A stronger evidence base is needed to better understand what types of SRH interventions work for which populations of young people in a given context, as well as what 
components of effective interventions might be common across those different interventions. This review also explored the psychosocial components of interventions to better understand common psychosocial practice elements of SRH interventions.

Given the high rates of mental health problems among young people in humanitarian and fragile settings and the strong link between mental health problems and sexual risk behaviors, incorporating trauma-informed psychosocial components into SRH interventions could improve SRH outcomes, particularly those related to service use. Findings from this review could help inform the development of integrated health promotion and prevention policies and programs to address the significant combined burden of poor SRH and mental health outcomes for vulnerable populations of young people in LMIC and humanitarian settings.

\section{Methods}

This systematic reviewed followed the Preferred Reporting Items for Systematic Reviews and Meta-Analysis (PRISMA) statement and standards for systematic reviews [23]. This review was registered in the PROSPERO database (Prospero \# CRD42019123233).

\section{Search strategy and selection criteria}

SRH search terms were selected based on the standard definition from the International Conference on Population Development (1994) and the World Health Organization's (WHO) SRH strategies and guidance (2010). Search terms for SRH were generated by the authors in consultation with a WHO librarian and encompassed the following: general sexual and reproductive health, pregnancy, family planning, contraception, abortion, prenatal healthcare, antenatal health care, HIV/AIDS, STIs, prevention of mother-to-child transmission (PMTCT), maternal and newborn health, gender-based violence, and adolescent sexual health. We included studies conducted in the Middle East, low-income, lower-middle income, and middle-income countries as defined by the current World Bank country classifications using individual country names in the search. In addition to general humanitarian-crisis related terms, the WHO designations for current humanitarian emergencies (at levels 1,2, and 3) were also used to guide identification of humanitarian settings. These included any type of humanitarian crises whether, man-made or natural disasters. We focused on LMICs because the resources available to address humanitarian crises in these settings are much different than those available in high-income countries, and a significant proportion of displaced persons seeking refuge from humanitarian emergencies are hosted by developing countries [2].
Our search strategy used the following format: (SRH related terms) and (intervention or education related terms) and (country/setting related terms). We restricted the search to randomized controlled trials, adolescent and young adult (ages 13-29) populations, and publications in the English language. We included studies only in peer-reviewed journals published between 2000 and 2018 and searched the following four databases: Pubmed, Psycinfo, Medline, and Embase. We then conducted a second search of upper-middle income countries using the same search strategy and hand-selected studies for title/abstract screening that were randomized controlled trials of SRH interventions among adolescents and/or young adults ages 13-29. We conducted this additional search in upper-middle income countries in order to more thoroughly review the literature on effective SRH interventions for young people. We also searched the grey literature by targeting international organizations involved in humanitarian work and reviewing any listed publications that included our SRH search terms. Finally, reference lists of prior systematic reviews on SRH domains in humanitarian settings were reviewed for potentially relevant studies. These multiple complementary search strategies helped ensure that we were as exhaustive as possible in our search strategy.

\section{Inclusion/exclusion criteria}

For studies in LMICs, we included only randomized controlled trials among adolescents and/or young adults ages 13-29. For Middle Eastern countries and humanitarian settings, we loosened our inclusion/exclusion criteria such that pilot randomized controlled trials and quasi-experimental designs among participants ages 1049 (those of reproductive age) were considered for inclusion because we anticipated that there might be few RCTs on SRH interventions among adolescents and young adults in these settings. We also included studies that focused only on mental health outcomes if they met all of our search criteria because identifying effective interventions for improving mental health in these settings could help identify effective approaches for addressing mental health concerns among those who also have unmet SHR needs as well as inform the development of psychosocial components of SRH intervention packages in these contexts. Relevant interventions that targeted our specified outcomes included: educational, psychosocial, prevention, community-based, psychoeducational, empowerment, mental health, psychological, counseling, family-based, and training programs.

Exclusion criteria were as follows: studies conducted in high-income countries, secondary analysis of primary data, and evaluations of non-relevant interventions (medical, pharmacological, dietary, exercise or cashtransfer interventions). 


\section{Data analysis}

All citations returned from the search databases and were downloaded and entered into a Microsoft excel database for screening of titles and abstracts based on our inclusion criteria. Data was then extracted from those studies selected for inclusion into another Microsoft excel database and subject to a secondary full text screening.

Extracted data included: first author, year of publication, title, trial duration, participant characteristics (age, gender), setting characteristics, country in which study took place, study design, type of intervention, intervention components, session topics (if available), recruitment incentives, follow-up incentives, intervention length, session format, follow-up duration, control condition, sexual and reproductive health outcomes, mental health outcomes and key findings.
For primary screening of titles and abstracts and secondary full text screening, two authors independently conducted screening and then cross-checked for consistency. Discrepancies were resolved via discussion between the two authors. If no agreement could be made, a designated third reviewer was consulted (see Fig. 1).

We used principles derived from a narrative approach for data synthesis and conducted a thematic analysis of included studies due to the diverse range of study outcomes and intervention approaches. The narrative synthesis approach is an iterative process that involves developing a theory about how and why the intervention works and developing a synthesis of findings for included studies [24]. Findings were analyzed by SRH outcomes, intervention components (SRH and psychosocial

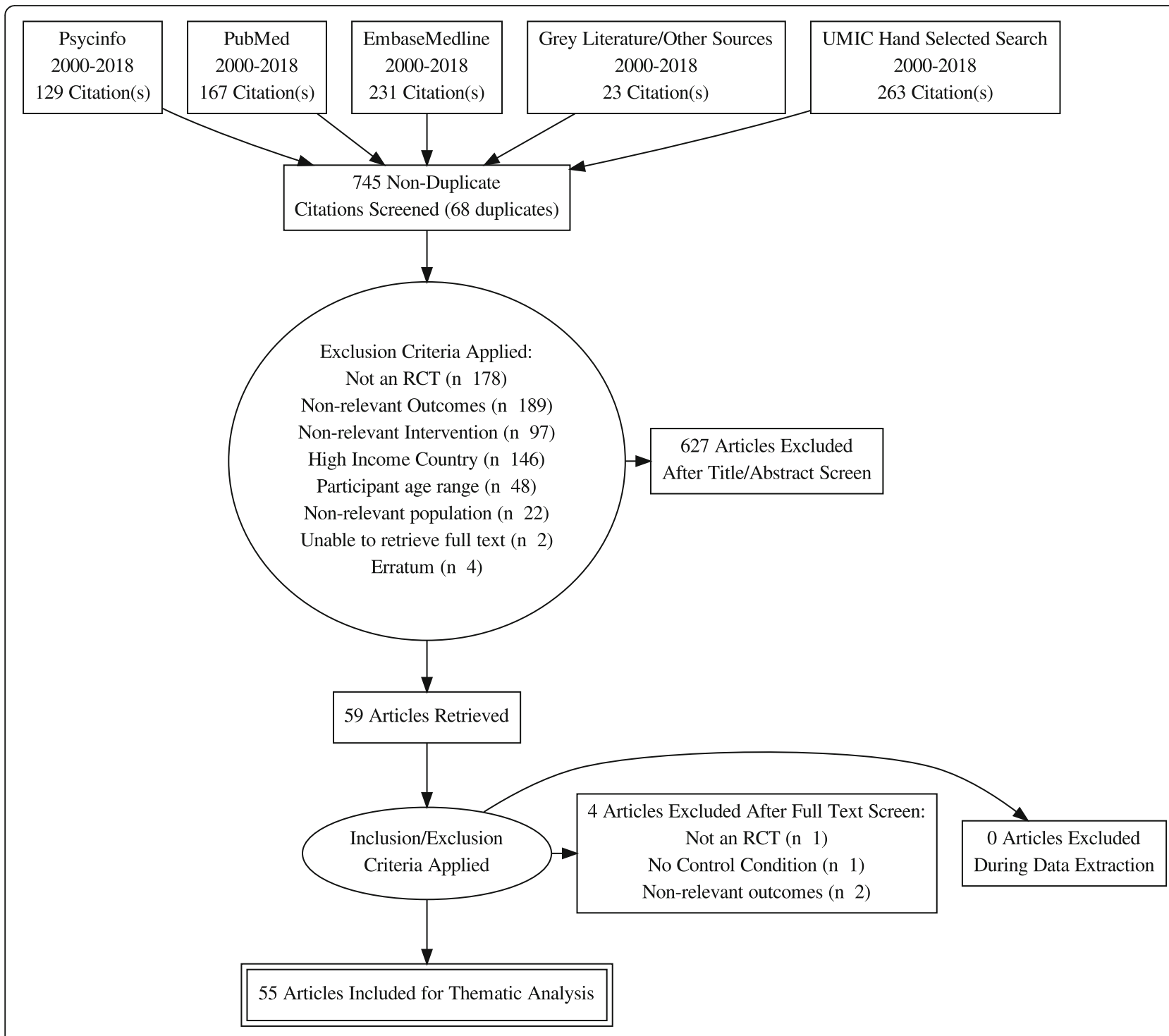

Fig. 1 PRISMA Flow Chart 


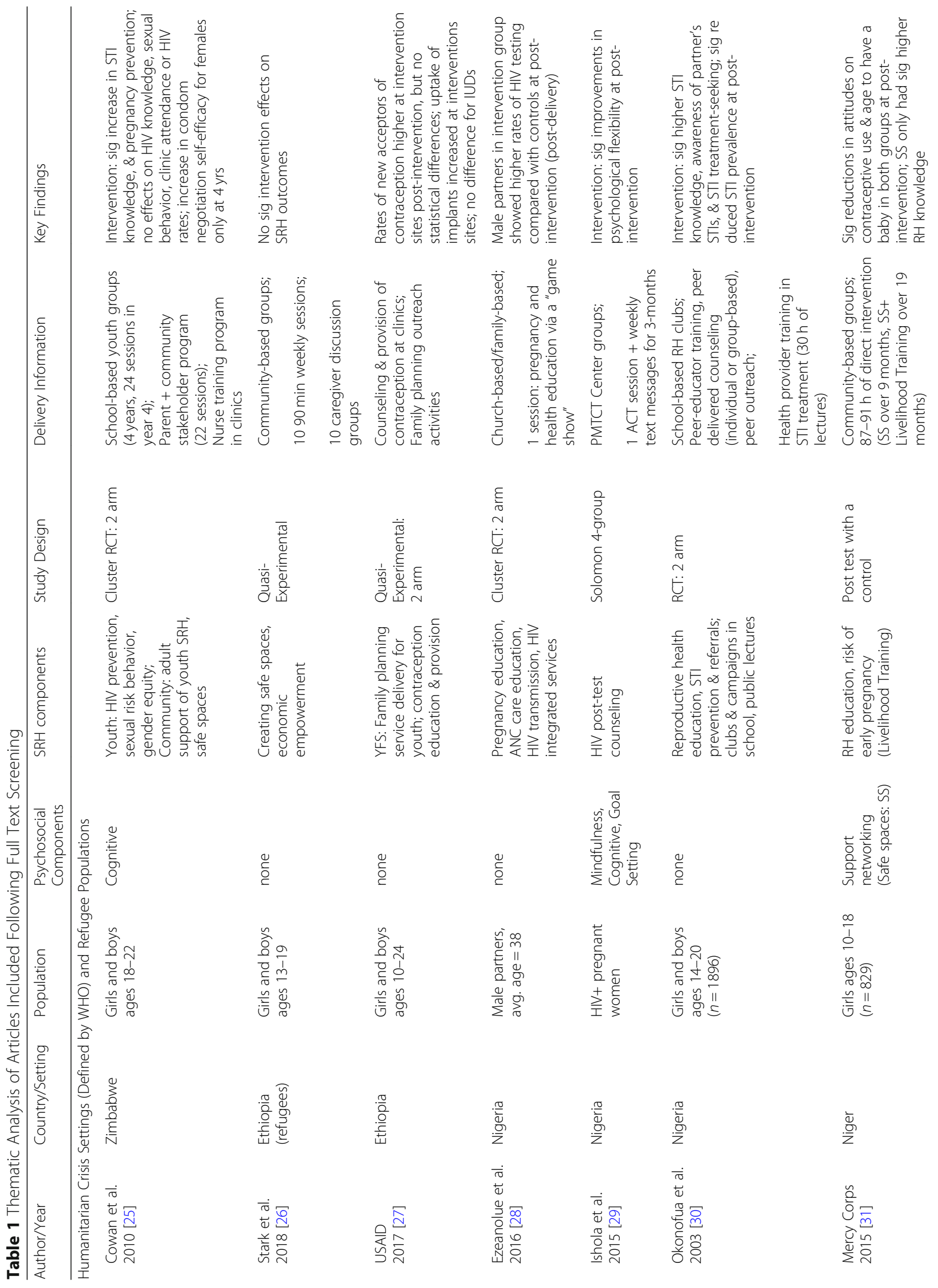




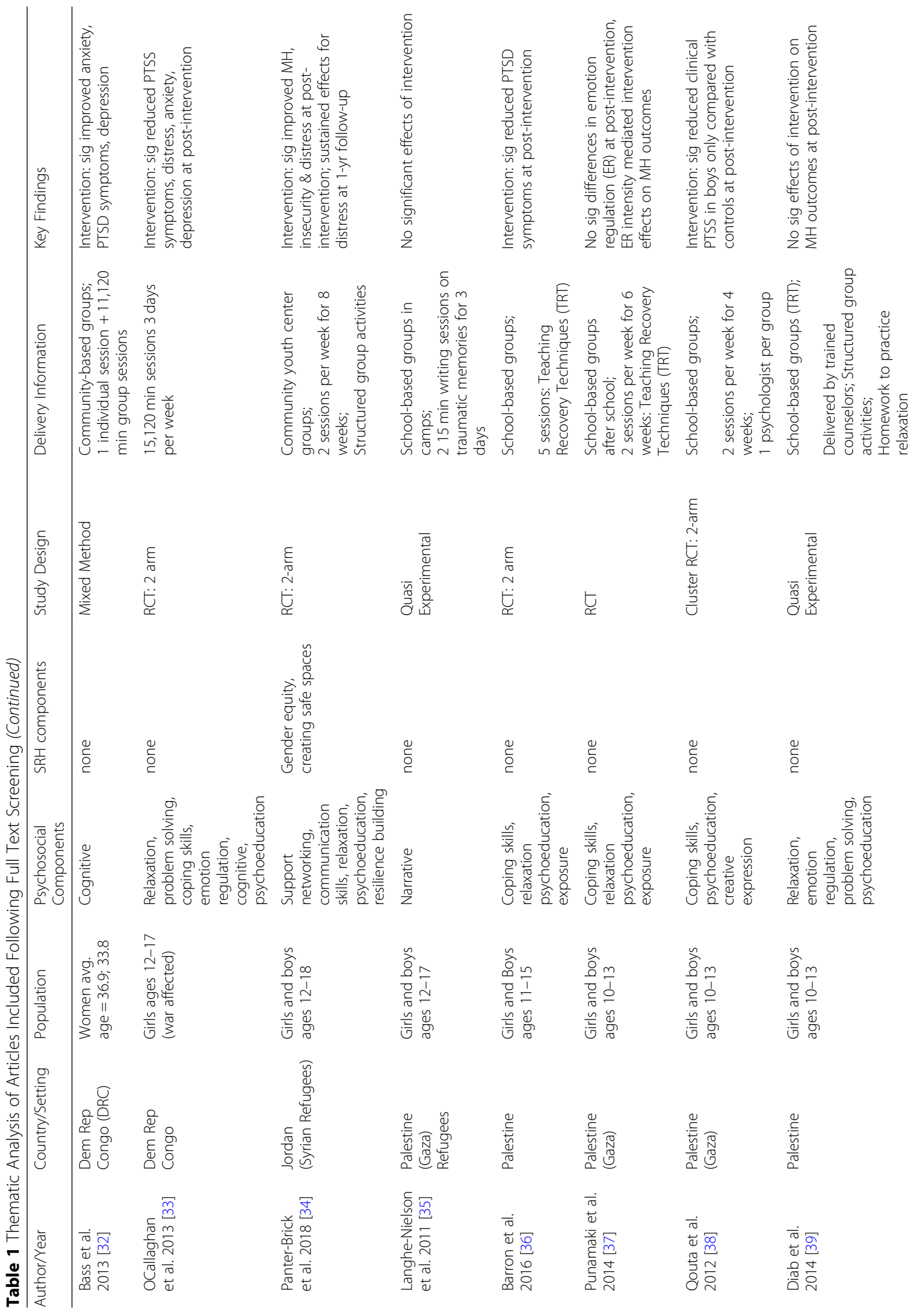




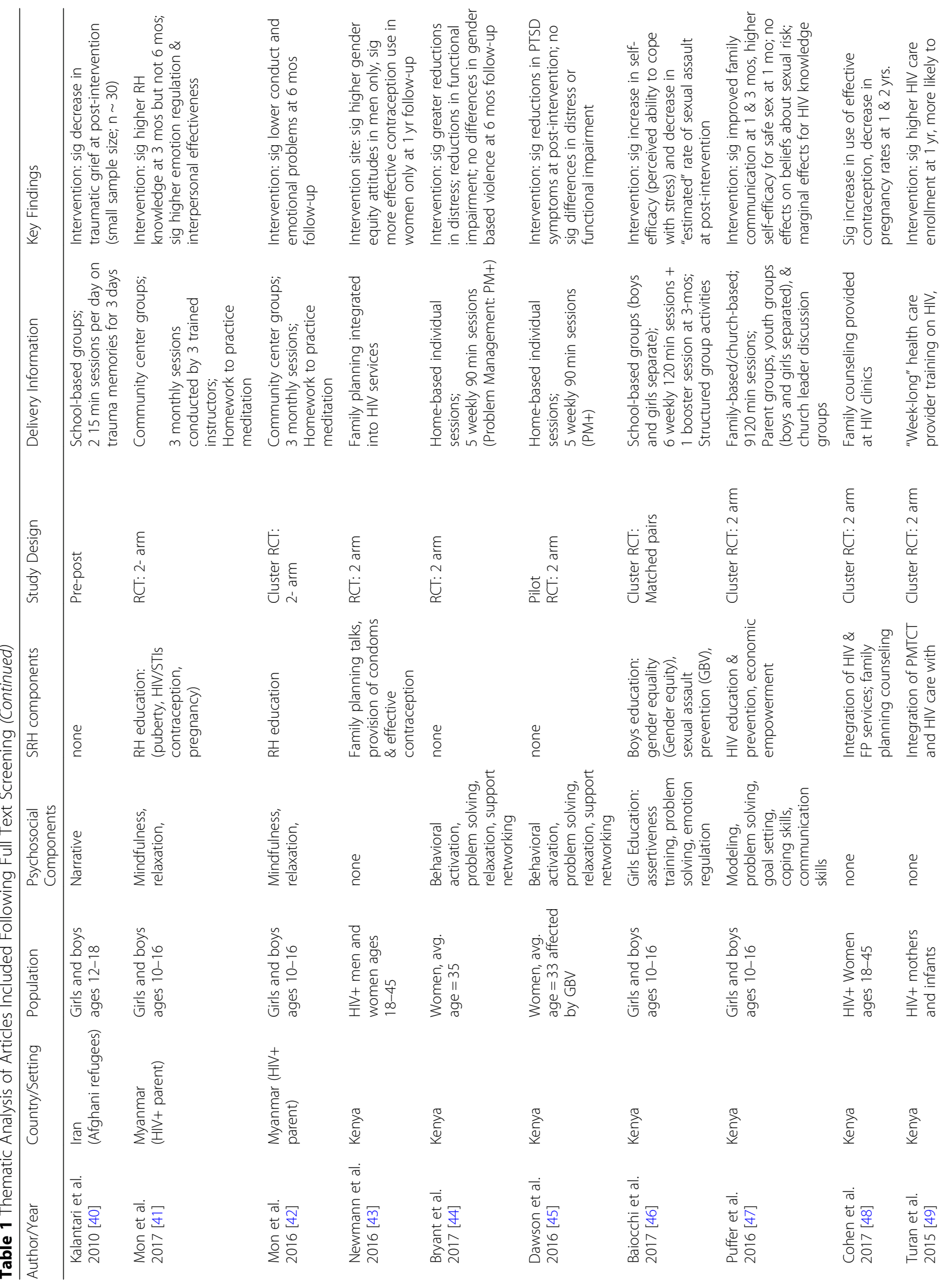




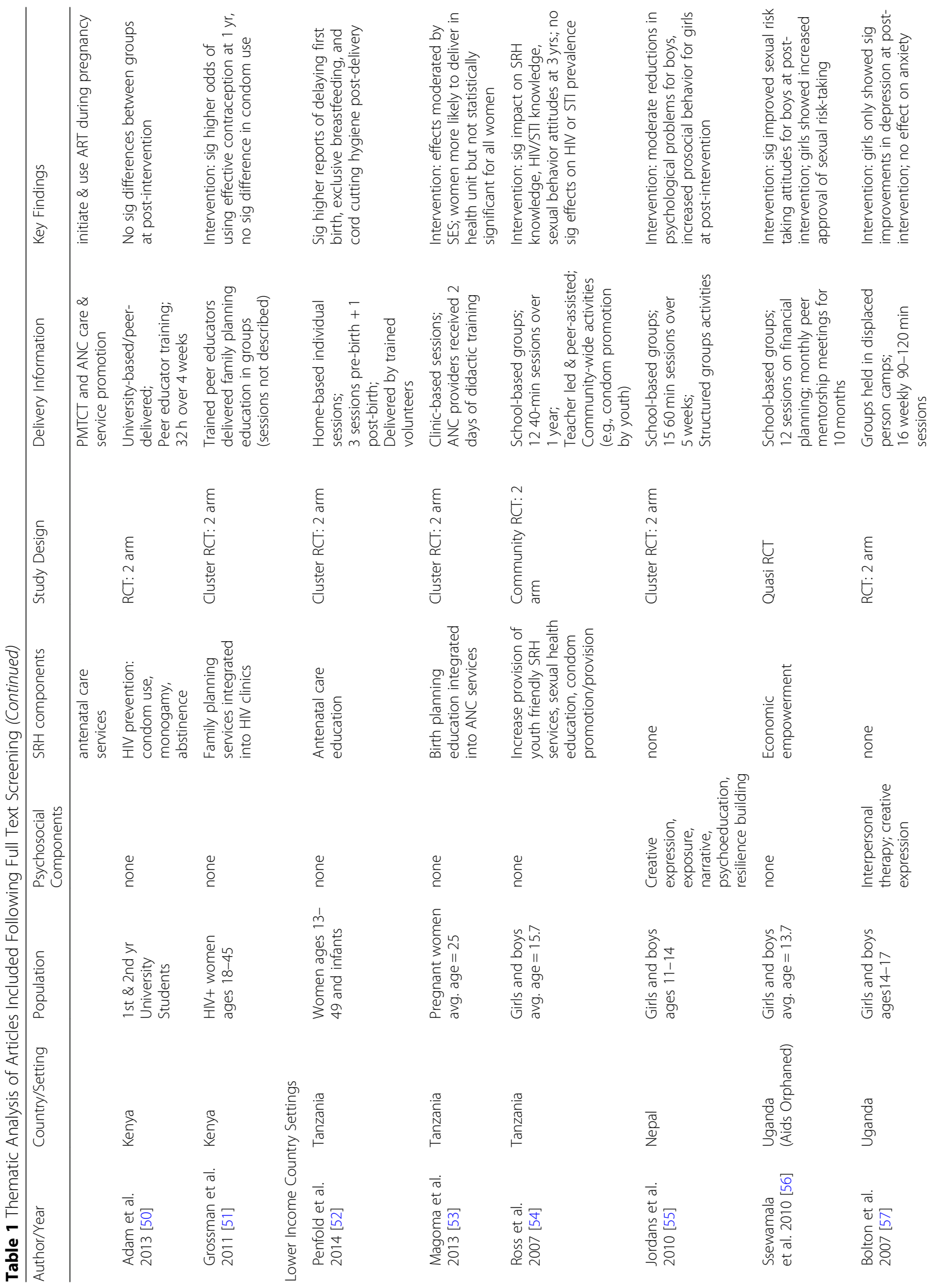




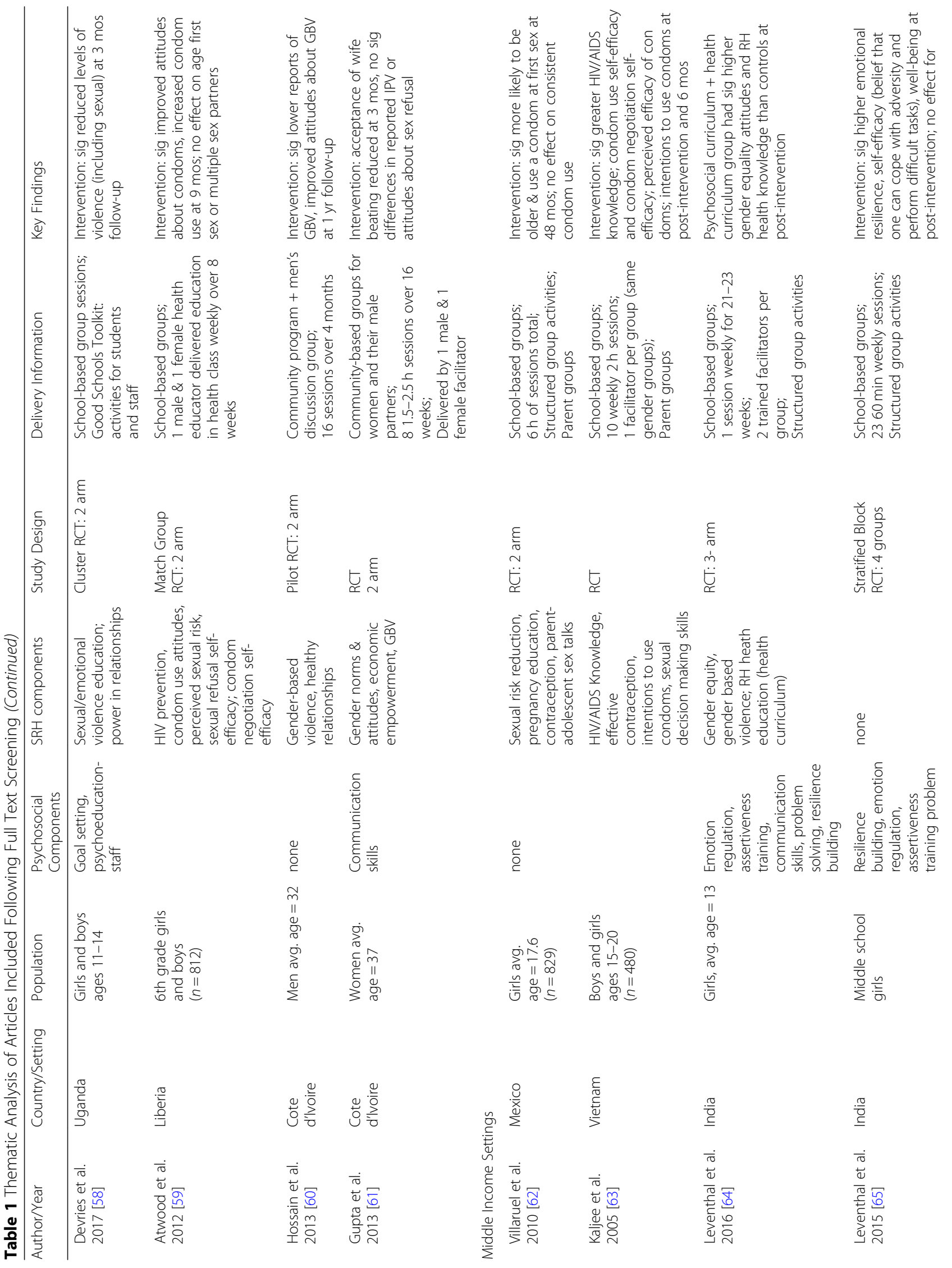




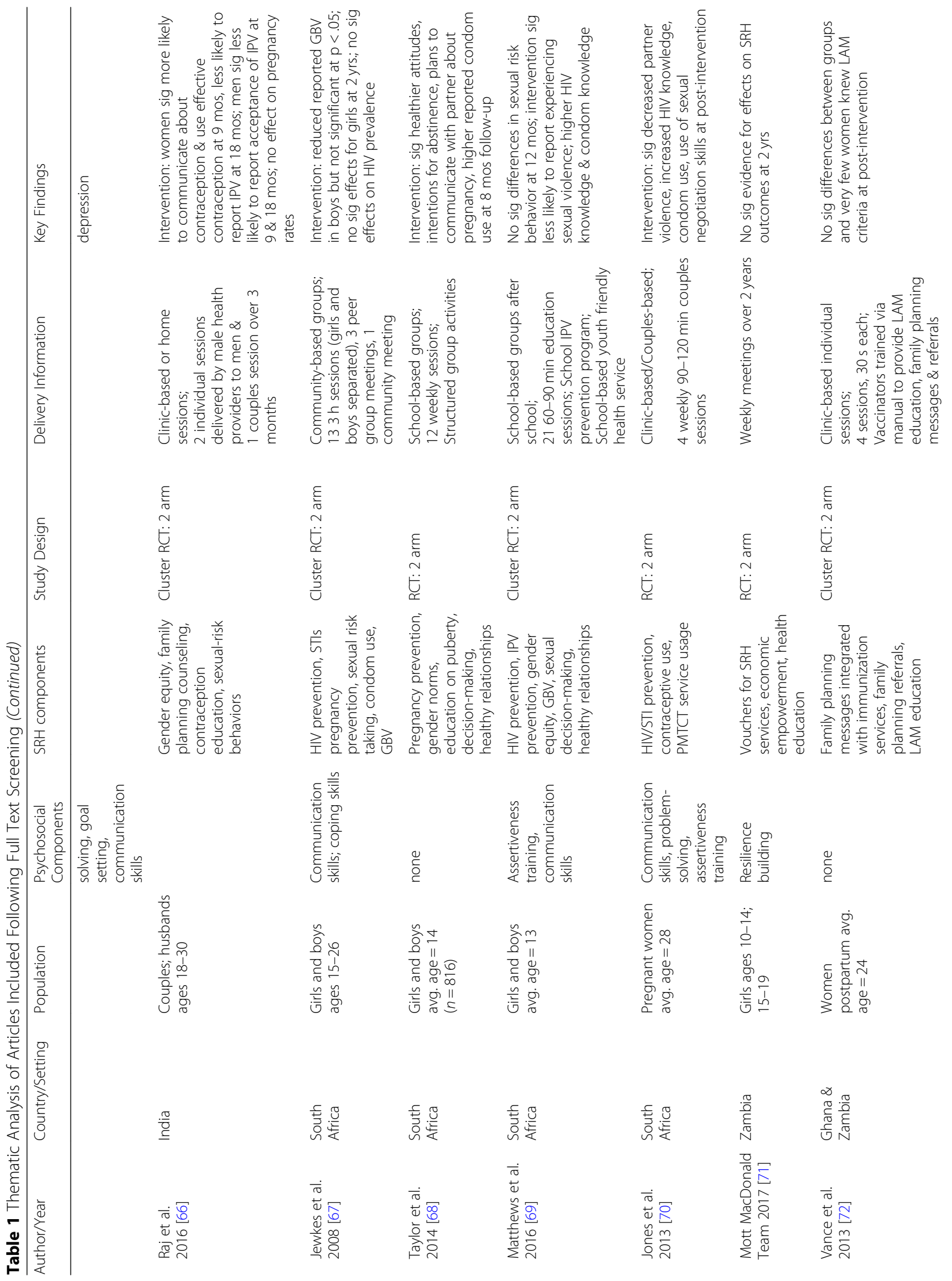




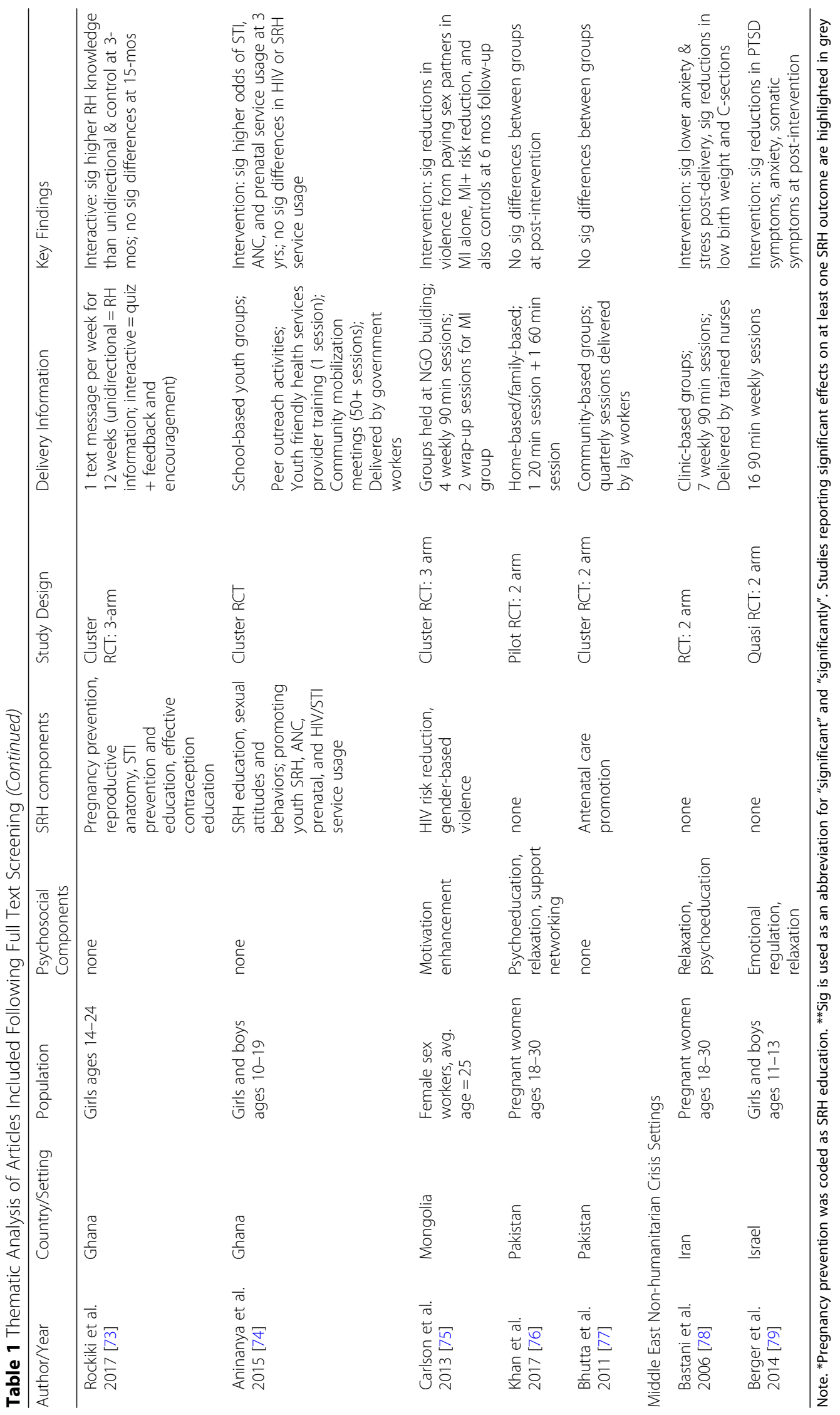




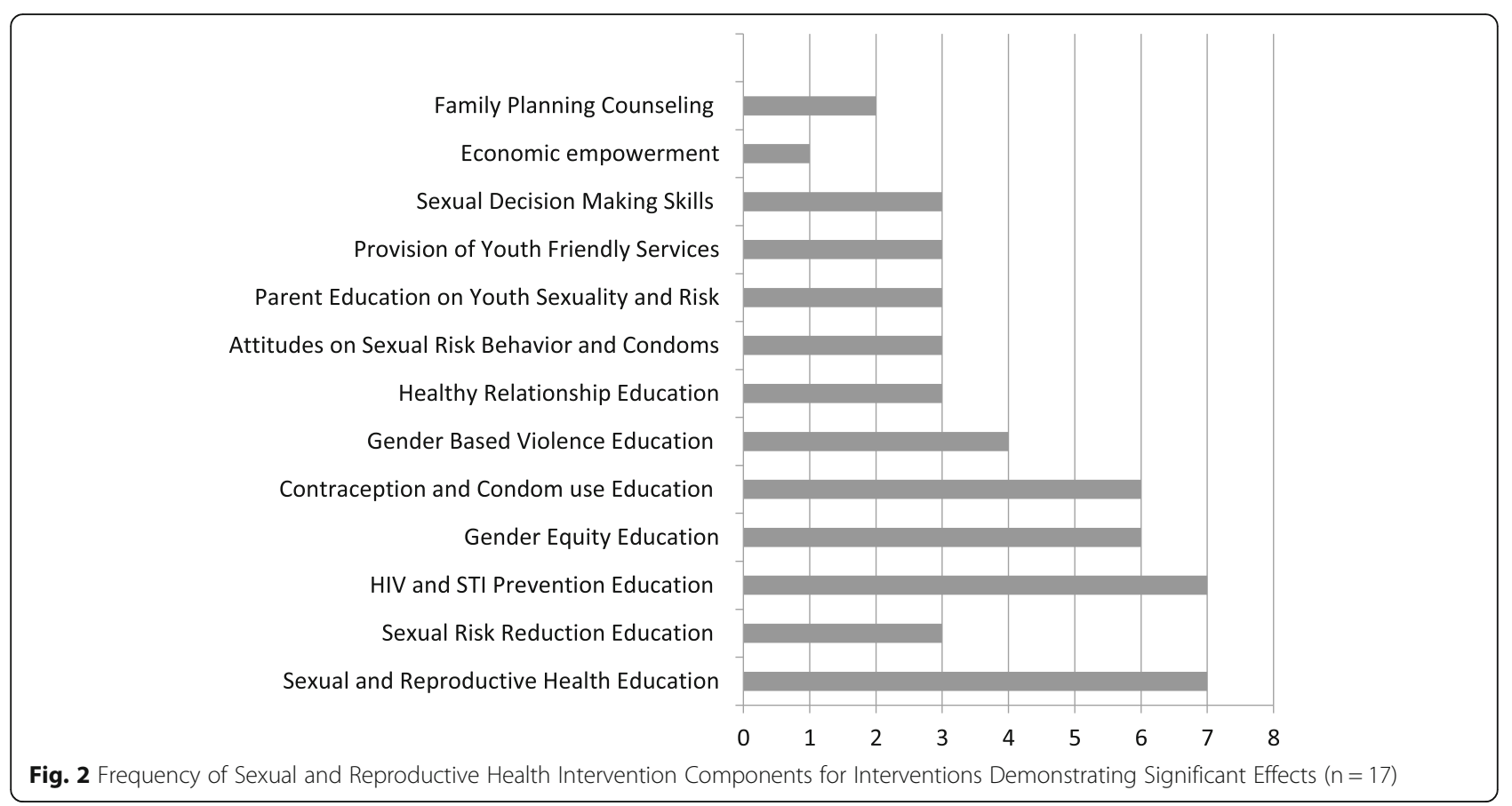

components), intervention delivery information, and key findings (see Table 1). Themes for SRH intervention components were developed iteratively after manually coding the papers and extracting relevant data. Coding for SRH intervention components was conducted by two coders and cross-checked for consistency. Psychosocial intervention components were coded using the Practice Wise Clinical Coding system [80], which is an empirically derived and tested system for identifying common practice elements across different interventions. There were four discrepancies in coding of psychosocial components. Discrepancies in coding were resolved by discussion until consensus was obtained. Intervention components that were not captured by the existing codes were recorded as free text and reviewed to generate additional practice codes, which were cross-checked by the second coder. We identified seven additional intervention practice codes: (a) emotion regulation, (b) resilience building, (c) coping skills, (d) creative expression, (e) self-efficacy, (f) behavioral activation, and (g) interpersonal skills.

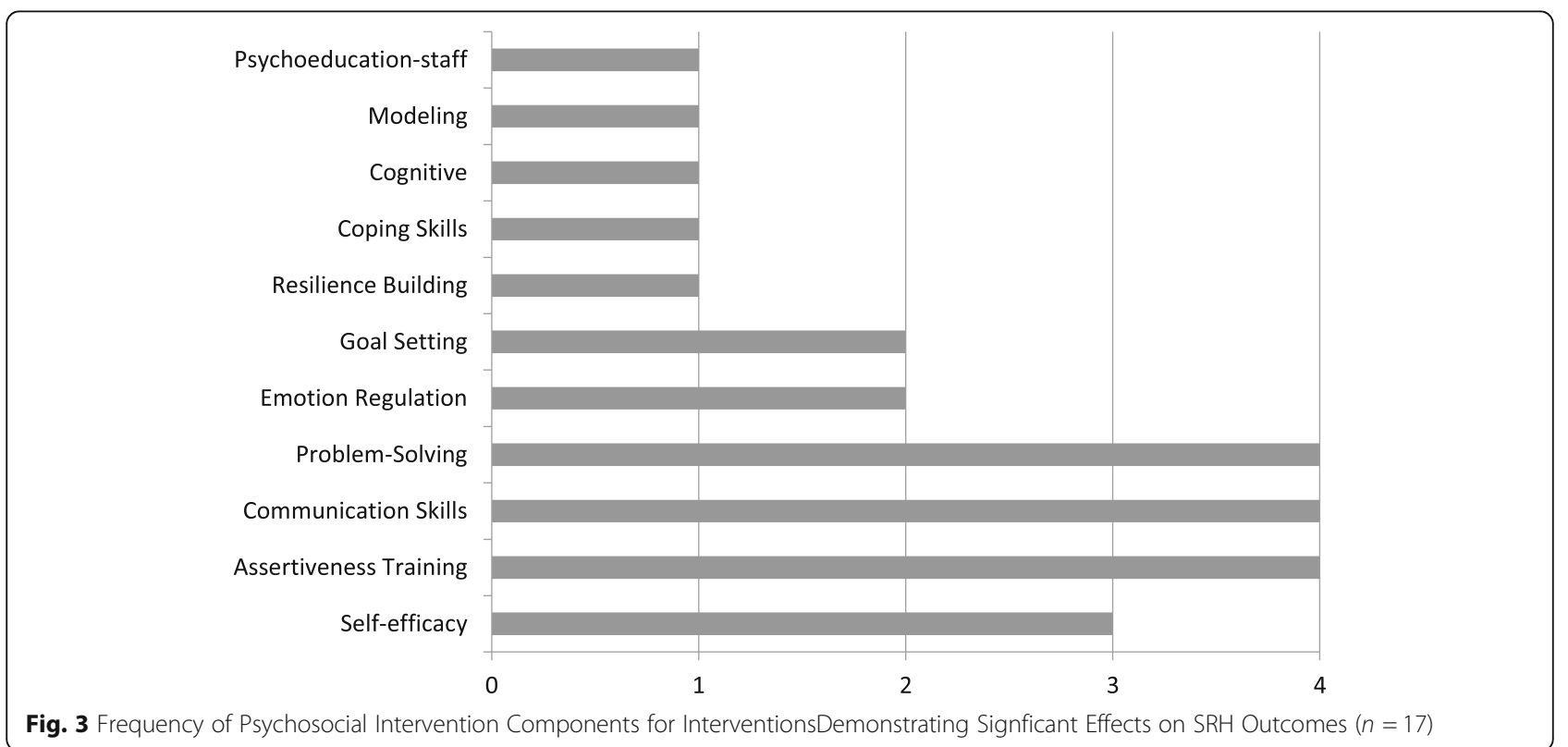


For those studies that reported significant effects of the intervention on SRH or mental health outcomes, summary charts illustrating common SRH and psychosocial components across studies were generated (see Figs. 2 and $3)$. Interventions were classified as effective by a significant between group intervention effect $(p<.05)$ in which the intervention group demonstrated significant improvements in one or more SRH outcomes at the final followup assessment in comparison to the control group or to another intervention group. For studies reporting moderator effects where significant effects on given SRH outcomes were reported only for specific sub-groups, these effects are described in Table 1 . In cases where moderation was reported, those SRH interventions that reported overall treatment effects or significant effects by gender were considered effective interventions; other moderation effects were not sufficient for an intervention to be considered effective [81]. In our presentation of findings, we focused primarily on those studies demonstrating effectiveness for SRH outcomes and not those that focused exclusively on mental health intervention components and outcomes because a systematic review focusing exclusively on mental health and psychosocial interventions for improving SRH among youth in LMIC and humanitarian settings was conducted previously (Turner et al., 2018; Prospero \#: CRD42018081410).

In order to further extract data on common intervention components for those interventions designated as effective, written requests were sent to the authors of papers describing effective SRH interventions to obtain intervention manuals and protocols. Follow-up requests were sent to authors who did not respond $(n=7)$. An online literature search for intervention manual materials was also conducted when authors failed to respond to follow-up requests. Common SRH and psychosocial components were identified through extracting data from intervention manuals, when available, or through the description of intervention components provided in the text of the journal article in cases where treatment manuals were not available $(n=8)$. Two independent raters reviewed intervention manuals and journal articles to extract core psychosocial intervention components. In cases where there was discrepancy $(n=2)$, a third rater reviewed intervention material and consensus was arrived at through discussion.

Methodological reporting quality of included studies was assessed using the Effective Public Health Practice Project (EPPHP) Quality Assessment Tool for Quantitative Studies [82]. Several modifications similar to those described by Brown et al., 2016 were made to better characterize aspects of methodological quality in light of the limited information provided in some studies. Two raters assessed methodological questions independently, and discrepancies were resolved through discussion.

\section{Results}

Results of the search strategy are summarized in the Prisma Flow chart (see Fig. 1). The literature search, review of grey literature, and reference list review yielded 813 results, 745 of which were non-duplicate citations. After title and abstract screening of the 745 studies, 686 were excluded. Full text screening was performed for 59 studies. Four studies were excluded following full text screening, yielding 55 studies for inclusion in thematic analysis. Table 1 presents a summary of the thematic analysis for included studies. 38 out of 55 studies evaluated SRH outcomes, and 17 of these studies reported significant intervention effects on one or more SRH outcomes in our primary population of interest (ages 1329). For the purposes of consolidating key findings of this review, we discuss below the results from thematic analysis of these 17 studies that reported intervention effectiveness on SRH outcomes over time among adolescents and young adults. Additionally, studies that reported significant effects for populations of adults over age 29 are presented in the thematic analysis table but not discussed in the summary of results because our primary focus was on effective interventions for SRH in adolescent and young adult populations. SRH outcome categories were centered on: (a) effective contraception and condom use skills, (b) HIV/STI prevention and education, (c) sexual self-efficacy, (d) SRH knowledge and education, (e) gender-based violence education. The majority of studies assessed multiple SRH outcomes and some incorporated psychosocial intervention components (see Table 1).

\section{Effective contraception and condom use skills}

We identified eight studies that reported improvement in outcomes related to effective contraception or condom use, intentions to use contraception or condoms, or attitudes about contraception or condom use. All studies were randomized controlled trials except for the Mercy Corps (2015) report [31], which used a "post-test with control" design. Villaruel et al. (2010) evaluated the effects of a school-based sexual risk reduction intervention, "the Cuidate Program", on youth in Mexico and found that those who received the intervention were significantly more likely to use a condom (OR, 1.75; 95\% CI, 1.14-2.69; $P<0.05$ ) or other contraception (OR, 1.53; 95\% CI, 1.00-2.33; $\mathrm{P}<0.05)$ during their first sexual encounter than those in the control group at 48month follow-up [62]. However no effect was found for consistent condom use over time. Kaljee et al. (2005) examined the effects of an HIV/STI prevention intervention delivered in schools among Vietnamese youth and found that those who received the intervention reported significantly greater intentions to use condoms $(p<.05)$ and perceived efficacy in condom use skills $(\mathrm{p}<.05)$ 
compared with those in the control condition at postintervention and 6-month follow-up [63]. The authors were unable to measure condom use behavior due to low reported sexual intercourse. In a study of integrated family planning counseling services into HIV clinics among young women in Kenya, those who received integrated services reported significant increases in use of effective contraception (from 31.7 to $44.2 \%$ of encounters) at 24-month follow-up compared with controls and decreases in pregnancy rates at 48-month follow-up compared with controls at year one (rate ratio: $0.72 ; 95 \% \mathrm{CI}$ 0.60-0.87) [48]. Atwood et al. (2012), examined an adapted version of "Making Proud Choices", an HIV/STI and pregnancy prevention curriculum, delivered in schools for 6th grade youth in Liberia and found that youth who received the intervention reported significant improvements in positive attitudes towards condoms at 3 -month and 6-month follow-up $(\beta=.12, p<.05 ; \beta=.08$, $\mathrm{p}<.05)$ [59]. Self-reported condom use self-efficacy was also significantly higher among those who received the intervention at 3-months and 9-months follow-up $(\beta=.08, \mathrm{p}<.05 ; \beta=.07, p<.10)$ compared with those in the control condition. Among youth who were sexually active, there was a significant effect on frequency of consistent condom use among those who received the intervention compared with controls at 9-month follow-up $(\beta=.34, \mathrm{p}<.05)$. Taylor et al. (2014) investigated a pregnancy prevention intervention delivered in schools for adolescents in South Africa and found that those who received the intervention reported significantly higher condom use than those in the control $(54.2 \%$ vs. $36.7 \%$, $p<.01$ ) [68].

Mercy Corps (2015) evaluated a Safe Spaces program compared with Safe Spaces in combination with a livelihood education program and a control condition delivered in schools and homes for girls (ages 10-18) in Niger [31]. The Safe Spaces program incorporates education on life skills, risk associated with early marriage and pregnancy, and reproductive health knowledge, whereas livelihood education focuses on savings and loan information, livestock management, and gardening. The authors reported significant improvements in attitudes towards contraception use in both those who received Safe Spaces $(\mathrm{p}<.01)$ and those who received Safe Spaces plus Livelihood $(p<.05)$ compared with controls. Matthews et al. (2016) evaluated a school-based HIV and intimate partner violence (IPV) prevention program among youth in South Africa and found that youth who received the intervention reported significantly greater condom knowledge than youth in the control condition at 12-month follow-up $(p<.001)$ [69]. The program involved an educational program during school delivered by study research staff, a youth friendly health service in school, and a peer-outreach component to spread information on violence prevention in school. Raj et al., (2016) evaluated a couples-based gender equity and family planning intervention among young married couples in India and found that women in the intervention group were significantly more likely to use effective contraception at 18-month follow-up (AOR $=1.57-1.58$, $p=0.05$ ) [66]. In a couples-based HIV risk-reduction and PMTCT intervention delivered to young couples in ANC clinics in South Africa, participants in the intervention group had greater odds of increased condom use at post-intervention compared with those in the control group $(\mathrm{OR}=5.1,95 \% \mathrm{CI}(\mathrm{OR})=(2.0,13.3)[70]$.

\section{HIV/STI prevention and education}

We identified six studies that reported significant improvements in HIV/STI knowledge, reductions in selfreported STI symptoms or increases in STI service usage. In a study investigating a multi-pronged HIV prevention intervention that included a youth, parent, and community component in Zimbabwe, youth (ages 18-22) who received the intervention reported significantly higher STI knowledge compared $(\mathrm{AOR}=1.32$; 95\% CI: $1.08-1.61)$ and pregnancy prevention $(\mathrm{AOR}=$ 1.59; 95\% CI:1.27-1.99), but no differences were found on HIV knowledge [25]. Aninyana et al. (2015) evaluated an SRH education intervention that involved a school-based curriculum for youth, peeroutreach activities, and youth friendly services provider training and found that youth who received the intervention demonstrated higher odds of STI service usage (AOR 2.47; 95\%CI: 1.78-3.42), but no significant differences on HIV testing service usage [74]. Another study that investigated an intervention involving school-based educational sessions delivered by teachers, community activities (i.e., community-based condom promotion by youth), and provision of youth friendly services found that youth who received the intervention reported significantly greater HIV transmission knowledge (male rate ratio: 1.44 (1.25, 1.67); female rate ratio: $1.41(1.14,1.75))$, and greater STI transmission knowledge (male rate ratio: 1.28 (1.07, 0.54); female rate ratio: $1.41(1.06,1.88))$ [54]. Okonofua et al. (2003) evaluated an intervention to improve STI treatment seeking that incorporated education on STI prevention and referrals to STI services in a school-based curriculum as well as series of community educational lectures and found that youth who received the intervention reported significantly increases in STI knowledge (mean increase in STI's named was .63 compared with the control group, 95\% CI: $0.39-0.86$ ) and STI treatment-seeking (from 17.5 to $40.7 \%$; OR $=3.24,95 \%$ CI: $1.84-5.74$ ) [30]. The authors also reported significantly reduced STI prevalence $(\mathrm{OR}=0.68,95 \% \mathrm{CI}=0.48-0.95)$ compared with 
youth in control schools at post-intervention. In the school-based HIV and IPV prevention program reported by Matthews et al. (2016), youth who received the intervention reported significantly greater HIV knowledge than those in the control arm at 12-month follow-up $(p<.01)$ [69]. Finally, the HIV/STI prevention intervention for youth in Vietnam also reported significantly greater HIV/STI knowledge among youth who received the intervention $(p<.05)$ compared with youth in the control condition at post-intervention and 6-month follow-up [63]. Jones et al. (2013) also found increased HIV knowledge at post-intervention among young couples completing the HIV-risk reduction intervention $(\mathrm{F}(1,476)=13.9, p<.001)$ [70]. All studies were randomized controlled trials.

\section{Sexual self-efficacy}

Four studies reported significant effects for sexual selfefficacy, including condom negotiation self-efficacy, self-efficacy for safe sex, and sexual refusal self-efficacy. In the study of an HIV prevention intervention among youth in Zimbabwe mentioned above, Cowan et al. (2010) found that female youth who participated in the intervention reported significant increases in condom negotiation self-efficacy compared with those in the control condition (AOR:1.17; 95\% CI: 0.95-1.43), but no significant differences were found for male youth [25]. Similarly, Baioochi et al. (2017) investigated a school-based program to increase girls' empowerment and boys' education about gender equity among youth (ages 10-16) in Kenya, and those who received the intervention reported significant increases in general self-efficacy, described as perceived ability to cope with stress and manage difficulties (mean score increase $=$ .19, 95\% CI: 0.08-0.39) [46]. Finally, in a study on a church-based HIV prevention intervention for youth and families in Kenya, youth who received the intervention reported increases in self-efficacy for safe sex compared with controls at 1 -month follow-up $(b=.41$, $p<.01$ ), but effects were not sustained at 3-month follow-up [47]. In the study on the HIV prevention intervention among youth in Vietnam, youth who received the intervention reported increases in condom use self-efficacy and condom negotiation self-efficacy compared with those in the control condition $(p<.001)$ at post-intervention and 6-months follow-up. All studies were randomized controlled trials [63].

\section{SRH knowledge}

We identified three studies that found significant intervention effects for improving accurate SRH knowledge. Leventhal et al. (2016) examined a psychosocial curriculum plus a health curriculum compared with the psychosocial curriculum alone and a control condition delivered in schools among girls in India (average age $=$ 13) [64]. The authors found that those who received both the health and psychosocial curriculum combined and the health curriculum alone reported significantly greater reproductive health knowledge (i.e., menstrual hygiene) than girls in the control condition $(p<.05)$ at post-intervention. The study by Ross et al. (2007) among youth in Tanzania reported that those who received the SRH intervention reported significant increases in pregnancy prevention knowledge (male rate ratio: 1.66; 95\% CI: $1.55-1.78$; female rate ratio: 1.58 ; $95 \%$ CI: $1.26-1.99$ ) compared with those in the control condition [54]. In the Mercy Corps (2015) study evaluating Safe Spaces alone and Safe Spaces plus a livelihood-training component among girls in Niger, both groups demonstrated significantly greater SRH knowledge compared with controls [31]. Girls in Safe Spaces were 69.7\% more likely to know one benefit of delaying pregnancy to 18 or older $(p<.01)$, whereas girls in the livelihood program were $27.7 \%$ more likely $(\mathrm{p}<.05)$.

\section{Gender-based violence and gender equity}

Five studies were identified that reported improvements in gender-based violence. Matthews et al. (2016) found that youth who received the HIV and intimate partner violence (IPV) prevention intervention were significantly less likely to report experiencing sexual violence than those in the control arm at 12-month follow-up (35.1 vs. 40.9\%; OR 0.77, 95\% CI 0.61-0.99; t [30] = 2.14) [69]. Devries et al. (2017) investigated the Good Schools Toolkit, which includes education on sexual and emotional violence and relationship power, among youth in Uganda (ages 11-14) [58]. The authors found that those who received the intervention reported significant reductions in levels of violence (male student $\mathrm{AOR}=0.34$, 95\% CI: 0.22-0.53; female students AOR $=0.55$, 95\% CI: $0.36-0.84)$. In the school-based curriculum developed by Baiocchi et al., (2017), results also showed that following the girls' empowerment and boys' gender equality education intervention components, there was an estimated $3.7 \%$ decrease ( $p=0.03 ; 95 \%$ CI: $0.4-8.0)$, risk of sexual assault in the intervention group [25]. Raj et al. (2016) found that of those participating in the gender equity intervention, women were less likely to report IPV $(\mathrm{AOR}=0.48, p=0.01)$, and men were less likely to report acceptance of IPV in comparison to those in the control condition at 18 -month follow-up (AOR $=0.51$, $p=0.004$ ) [66]. In the couples-based HIV-risk reduction intervention in South Africa, there was a significant reduction in reported acts of violence and verbal aggression among those in the intervention group (McNemar's test, $p=0.001$ for intervention, $p=0.49$ for control; McNemar's test, $\mathrm{p}=0.01$ for intervention, $p=0.10$ for control, respectively) [70]. 


\section{SRH intervention components}

The SRH components of intervention packages demonstrating significant effects on SRH outcomes focused primarily on education/knowledge building and skills building. The most frequent educational components were: SRH education (i.e., puberty, reproductive anatomy, pregnancy; 7/17), HIV/STI prevention education (7/17), gender equity education (6/17), and education about effective contraceptive methods (including condom use) (6/17). Education on gender-based violence was the next most common component (4/17). Three studies also incorporated parent education sessions on youth SRH, and three included education on healthy relationships. For skill-building, sexual decision making skills components were incorporated in three studies, and building condom use skills through demonstration and practice was incorporated into those interventions focused on improving knowledge of effective contraceptive methods. Three studies incorporated youth friendly services as an intervention component to increase youth access to SRH services. For studies reporting pregnancy prevention as an SRH intervention component, we coded pregnancy prevention as SRH education.

\section{Psychosocial intervention components}

Of the 17 studies that reported significant intervention effects on SRH outcomes, approximately 50\% (9/17) incorporated psychosocial components into the intervention package. The most common psychosocial components included were assertiveness training $(4 / 17)$ communication skills (4/17), and problem solving (4/17), (see Fig. 3). Other common psychosocial intervention components included emotion regulation, goal setting, resilience-building, cognitive, modeling, coping skills, and psychoeducation-staff.

\section{Intervention delivery information}

The majority of the effective SRH interventions were delivered in school settings (13/17). Three of these interventions were delivered in multiple settings that included schools and either community centers or clinics. Other intervention delivery settings were clinics (3/17), churches (1/17) or village community settings (1/ 17). The most frequent delivery format for interventions was group-based (15/17), with two group-based interventions delivered to female youth only. Four interventions involved an individual counseling component, four involved parent education and discussion groups, and four involved a community component (i.e., community outreach activities, public lectures, etc.). Multicomponent intervention approaches that included youth groups and either a parent group or community component (or both) were also reported in 8/17 studies. Three studies incorporated peer outreach training. Two studies involved couples-based interventions that included male partner involvement. Four studies incorporated service provider training for SRH services, and three of these implemented youth friendly health services as an intervention component. Only four studies described both facilitator training and supervision procedures; five studies provided some description of facilitator training procedures but failed to report on supervision. Interventions varied greatly in terms of session frequency, length, and overall duration of the intervention (see Table 1).

\section{Methodological quality}

Results of the quality assessment rating in accordance with the EPHPP criteria are displayed in Fig. 4. Studies reported strong participant study completion rates, with 11 studies indicating completion rates of $80 \%$ or higher, and only two studies failed to report participant withdrawal and dropout information. There were also several methodological weaknesses of these studies. A major methodological weakness was the failure to blind both participants and assessors or the lack of reporting about whether blinding occurred. Only one study reported that assessors were blinded, and no studies reported that participants were blinded to study condition. Another weakness was reporting of whether contamination likely occurred; only one study reported that participants in the comparison condition likely had some exposure to the intervention program. Many studies also failed to report information on the reliability or validity of assessment tools, with only four studies including information on validity and eight on reliability. Finally, only six studies described processes through which fidelity to the intervention was assessed or monitored, and no studies reported results of fidelity assessments.

\section{Discussion}

The current systematic review aimed to fill gaps in existing research by focusing on more rigorously evaluated $\mathrm{SRH}$ interventions for young people in LMIC and humanitarian settings to better understand which types of interventions demonstrated effectiveness. The review also aimed to examine the inclusion of psychosocial intervention components in those SRH interventions identified as effective. Findings suggest that there is preliminary support for the effectiveness of several evidence-based SRH interventions for young people in humanitarian and low resource settings, but additional research is needed, including replication studies, studies with longer follow-up periods, and studies focused on feasibility, implementation and sustainability of interventions on a broader scale. This is consistent with conclusions of the few prior reviews on SRH services for adult populations during humanitarian crises-the evidence- 


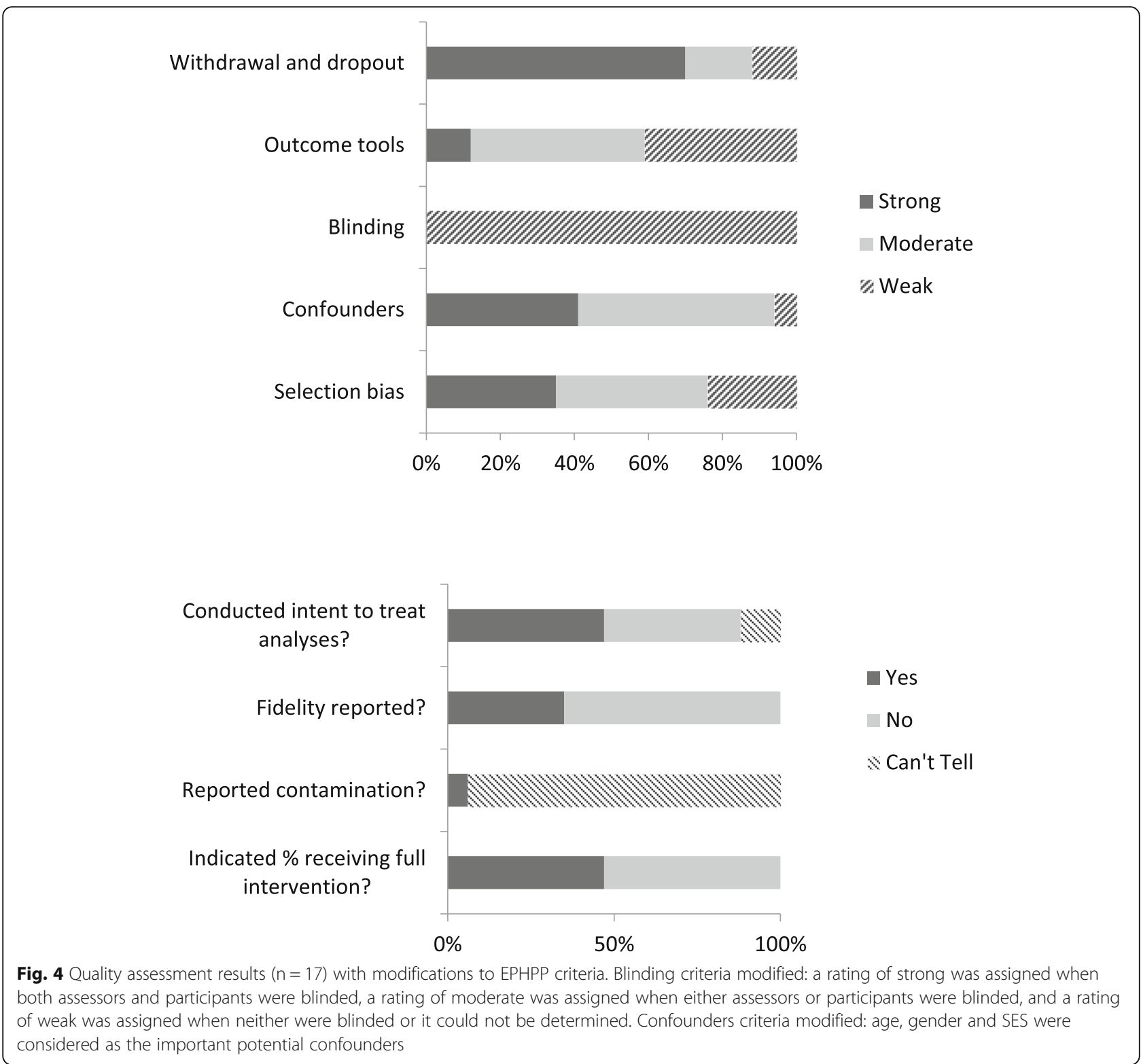

base for effective interventions is limited and more implementation research is needed $[7,8,83]$.

Of those SRH interventions determined to be effective, the most common SRH outcomes that improved over time were (a) effective contraception and condom use skills and (b) HIV and STI prevention knowledge) [30, 31, 48, 54, 59, 62, 63, 66, 68-70, 74]. Findings suggest that effective evidence-based approaches to improve knowledge about effective contraception and prevention of HIV and other STIs among young women and men in humanitarian and LMIC settings are available, but must be adapted to context and the realities of humanitarian emergencies (such as high levels of trauma exposure and loss). For resource limited areas and fragile contexts in which implementing high intensity interventions are challenging, incorporating education about these two key components of SRH in a trauma-informed manner could be viable options. Lower intensity approaches might also be more easily integrated into existing service systems or school-based health curriculum and still yield important improvements in SRH. Given that many of the effective interventions consisted of lengthy periods of delivery (e.g., 1-2 years of a program) that involved a high level of coordination and training, identifying key content areas of effective SRH interventions is crucial for identifying potential "active ingredients" to include in a deploymentfocused model [84] to facilitate greater feasibility and adoption of integrated SRH and psychosocial 
interventions for young people in the sorts of delivery settings available for populations affected by humanitarian emergencies. While beyond the scope of the current review, future research might explore whether the methods outlined in the common elements approach could be validly applied to identify common $\mathrm{SRH}$ elements of those interventions that failed to demonstrate effectiveness, which could help to better disentangle which components are less effective across studies.

Effective interventions tended to be delivered in a group format with similar age peers. The majority of these group-based interventions for school-aged youth were delivered in schools either during regular hours or as an extracurricular activity after school. There were vast differences in delivery format for school-based interventions, with intervention length ranging from six sessions to 24 sessions and session duration ranging from $40 \mathrm{~min}$ to $120 \mathrm{~min}$; therefore, it is difficult to ascertain which characteristics of SRH intervention delivery in school settings might be optimal for improving SRH outcomes or engaging young people. Multi-component interventions for adolescents that involved parents and community members were also common among those SRH interventions demonstrating effectiveness [25, 47, $62,63,74]$. This suggests that engaging parents and key community members in talks, support groups, and educational sessions related to SRH among youth could be an important component of effective SRH interventions. Engaging parents and community leaders could help raise awareness about youth sexuality and SRH concerns as well as decrease stigma related to seeking SRH services among youth. Interventions that involved parent sessions also focused on improving communication between young people and their families around SHR topics, which suggests that this may also be an important aspect of SRH interventions targeting youth.

Of those interventions that showed improvements in gender-based violence or gender equity awareness, nearly all interventions involved both young men and women, though interventions varied in terms of whether groups were separated by sex/gender and whether they were couples-based ( $n=2$ couples interventions). For the two couples-based interventions, one consisted of four weekly 90-120 min couples' sessions, whereas the other consisted of two individual sessions delivered by males to males and one couples-based session. This highlights the potential importance of involving and engaging young men for improving young women's sexual health, empowerment, and well-being. Investment in interventions that engage men in reproductive health, maternal health, and gender-based violence in LMICs has increased considerably in recent years [85-87]. thus further supporting the notion that male engagement is a critical component of addressing SRH in LMICs and humanitarian emergencies. Implementing SRH interventions that involve young men may be particularly important during adolescence and young adulthood, as this is a developmental period when norms and beliefs about gender are shaped and solidified.

Nearly half of the SHR interventions designated as effective incorporated psychosocial components into their session content $[25,46,47,59,63,64,69,70]$. However in those instances when psychosocial outcomes were also measured, information was not consistently provided as to whether participants reported improvements in psychosocial or mental health outcomes. Additional, potential associations between improvements in mental health or other psychosocial outcomes and SRH outcomes were not reported. Given the high prevalence of mental health issues among refugee and displaced populations of youth as well as the higher prevalence among women in comparison to men $[18,20]$. Future research would benefit from examining the links between psychosocial and SRH outcomes in intervention packages that include both components and to what degree the backdrop of trauma, common in populations affected by humanitarian emergencies, requires additional attention. In particular, assertiveness training and communication skills could be important psychosocial intervention components that could be incorporated into traumainformed intervention models to promote SRH outcomes like sexual self-efficacy (both condom/contraceptive negotiation self-efficacy and sexual refusal selfefficacy) and sexual decision-making skills. Additional research is needed to better understand which common psychosocial practice elements might be linked to improved SRH outcomes in LMIC and humanitarian contexts. As with SRH components, future research might consider whether the common practice elements approach could be feasibly applied to identify common psychosocial components of ineffective interventions, which could potentially provide information on which components are less useful or pertinent in achieving intervention benefits.

\section{Limitations}

We restricted our search to those studies published in the English language, which may have limited the number of articles retrieved from our search. Qualitative studies were excluded from the search, which can often provide rich information regarding feasibility and acceptability of interventions as well as guide selection of culturally appropriate incentives to improve participation and retention during intervention implementation. We limited our search to randomized controlled trials (with the exception that quasi-experimental studies conducted in humanitarian settings or the Middle East were 
included) in order to gather information on those SRH interventions that were evaluated through rigorous scientific methods, which may have limited the studies retrieved in low resource settings that lack funding and expertise for more costly evaluations of interventions. Because we restricted our participant age criteria to exclude studies that included participants ages 10 and under, we may have excluded some effective SRH interventions for adolescent populations if the study included younger participants. It should be noted that our criteria for including an intervention as effective were that the intervention demonstrated significant improvements in one or more of the reported SRH outcomes over time. There were several instances in which an intervention showed significant effects on one SRH outcome, while failing to impact several others (or impacting outcomes in unexpected directions for particular subgroups). We retained these studies because they still met our inclusion criteria, but the inconsistency in improvement across SRH outcomes raises some questions as to thus overall effectiveness of those interventions. Inclusion of some studies conducted in upper-middle income countries could be less relevant for populations in the Middle East and humanitarian settings due to cultural, social, economic, and political differences among these contexts; thus their findings may not necessarily generalize to humanitarian contexts. Heterogeneity of measurement tools used to assess SRH outcomes across studies and lack of psychometric information on outcome tools obfuscated comparison of effects across studies.

\section{Conclusion}

The current review offers a comprehensive summary of novel and effective SRH interventions for young people in LMIC and humanitarian settings. It describes these SRH interventions, highlights their novel strategies where possible, and describes the range of SRH outcomes that showed significant improvements. The review also includes a thematic analysis of intervention delivery characteristics, core intervention components and provides a quality assessment of the studies reporting effective SHR interventions for young people. Findings of this review provide some potentially useful insights for adaptation of evidence-based interventions for young people in different contexts and could inform decisions of key stakeholders to further invest in particular interventions for broader dissemination and scale-up in LMICs, the Middle East and humanitarian settings. Findings of this review may also be useful for public health and policy workers, as it could broaden their understanding of what works more effectively and for whom in fragile contexts, with the aim of improving SRH outcomes and related SRH service use among young people in these settings.

\section{Abbreviations}

SRH: Sexual and Reproductive Health; LMICs: Lower and Middle Income Countries; STIs: Sexually Transmitted Infections; HIV: Human Immunodeficiency Virus; MISP: Minimal Initial Service Package for Reproductive Health in Crisis; PRISMA: Preferred Reporting Items for Systematic Reviews and Meta-analysis; EPPHP: Effective Public Health Practice Project; IPV: Intimate Partner Violence; WHO: World Health Organization; PMTCT: Prevention of Mother-to-Child Transmission

\section{Acknowledgements}

Not applicable.

\section{Authors' contributions}

AD contributed substantively to the design of this work, to data collection, analysis, and interpretation, and to drafting the work. TB contributed to design of this work and to substantive revising of drafts of this work. YG contributed substantively to data collection, analysis and interpretation. CS contributed to conception and design of this work and interpretation of data. LS contributed substantively to conception of this work. LK contributed substantively to conception and design of this work, to data interpretation, and to revising the drafted work. All authors have read and approved the final version of this work and agree to be personally accountable for their contribution.

\section{Funding}

This study was supported by the Department of Sexual and Reproductive Health and Research, including the UNDP/UNFPA/UNICEF/WHO/World/Bank Special program of research, development and research training in human reproduction. The authors alone are responsible for the views expressed in this article, and they do not necessarily represent the views, decisions or policies of the funding bodies or institutions with which they are affiliated. The funders had no role in study design, data collection and analysis, decision to publish or manuscript preparation.

\section{Availability of data and materials}

The datasets used and/or analyzed during the current study are available from the corresponding author upon reasonable request.

Ethics approval and consent to participate Not applicable.

Consent for publication

Not applicable.

\section{Competing interests}

The authors declare that they have no competing interests.

\section{Author details}

${ }^{1}$ Boston College School of Social Work, 140 Commonwealth Avenue, Chestnut Hill, MA 02467, USA. ${ }^{2}$ Department of Sexual and Reproductive Health Research, World Health Organization, 20 Avenue Appia, 1211 Geneva 27, Switzerland

Received: 28 March 2019 Accepted: 30 April 2020

Published online: 12 May 2020

\section{References}

1. United Nations Office for Coordination of Humanitarian Affairs (OCHA). (2019). Global Humanitarian Overview, 2019.

2. United Nations High Commission for Refugees (UNHCR). Global Trends: Forced Displacement in 2017. 14th Edition, 2018. Accessed at: https://www. unhcr.org/globaltrends2017. Retrieved February 20, 2019.

3. United Nations Population Fund (UNFPA). Humanitarian Action Overview 2018. Retrieved https://www.unfpa.org/sites/default/files/pubpdf/UNFPA_ HumanitAction_18_20180124_ONLINE.

4. Fatusi A. Young people's sexual and reproductive health interventions in developing countries: making investments count. J Adolesc Health. 2016;59: S1-3.

5. Ivanova O, Rai M, Kemigisha E. A systematic review of sexual and reproductive health knowledge, experiences and access to services among 
refugee, migrant and displaced girls and young women in Africa. Int J of Environ Res Public Health. 2018;15:1-12.

6. Blanchet K, Ramesh A, Frison S, Warren E, Hossain M, Smith J. Evidence on public health interventions in humanitarian crises. Lancet. 2017;390:2287-96.

7. Casey SE. Evaluations of reproductive health programs in humanitarian settings: a systematic review. Confl Health. 2015;9:S1.

8. Kalamar A, Bayer A, Hindin M. Interventions to prevent sexually transmitted infections, including HIV, among young people in low-and-middle-income countries: a systematic review of the published and gray literature. J Adolesc Health. 2016:59:S22-31.

9. Morris J, Rushwan H. Adolescent sexual and reproductive health: the global challenges. Int J Gynecol Obstet. 2015;131:S40-2.

10. UNAIDS. Adolescent girls and young women. Geneva, Switzerland: Joint United Nations Programme on HIV/AIDS; 2014.

11. Askew I, Khosla R, Daniels U, Krause S, Lofthouse C, Say L, et al. Sexual and reproductive health rights in emergencies. Bulletin World Health Organization. 2016;94:311.

12. Barot S. In a state of crisis: meeting the sexual and reproductive health needs of women in humanitarian situations. Guttamacher Policy Review. 2017;20.

13. Singh NS, Aryasinghe S, Smith J, et al. A long way to go: a systematic review to assess the utilisation of sexual and reproductive health services during humanitarian crises. BMJ Glob Health. 2018;3:e000682. https://doi. org/10.1136/ bmjgh-2017-000682.

14. Singh SD, Darroch JE, Ashford LS. Adding it up: the costs and benefits in investing in sexual and reproductive health. 2014. New York: Guttmacher Institute; 2014.

15. Hindin MJ, Kalamar AM, Thompson T, Upadhyay UD. Interventions to prevent unintended and repeat pregnancy among young people in lowand middle-income countries: a systematic review of the published and gray literature. J Adolesc Health. 2016;59:S8-15.

16. Masterson A, Usta J, Gupta J, Ettinger AS. Assessment of reproductive health and violence against women among displaced Syrians in Lebanon. BMC Womens Health. 2014;14(25):2-8.

17. World Health Organization (WHO). WHO Fact Sheets, 2018. Retrieved from: https://www.who.int/news-room/fact-sheets/detail/adolescent-mentalhealth.

18. Turrini G, Purgato M, Ballette F, Nosè M, Ostuzzi G, Barbui C. Common mental disorders in asylum seekers and refugees: umbrella review of prevalence and intervention studies. Int J Ment Health Syst. 2017;11:51.

19. Kessler RC. Epidemiology of women and depression. J Affect Disord. 2003; 74(1):5e13.

20. World Health Organization (WHO). WHO Fact Sheets. 2018. Retrieved from: https://www.who.int/mental_health/prevention/genderwomen/en/.

21. Patton GC, Sawyer SM, Santelli JS, Ross DA, Afifi R, Allen NB, et al. Our future: a lancet commission on adolescent health and wellbeing. Lancet. 2016;387:2423-8.

22. Higgins A, Barker P, Begley CM. Sexual health education for people with mental health problems: what can we learn from the literature? J Psychiatr Ment Health Nurs. 2006;13:687-97.

23. Moher D, Liberati A, Tetzlaff J, Altman D, The PRISMA group. Preferred Reporting Items for Systematic Reviews and Meta-Analyses: The PRISMA Statement. J Clin Epidemiol. 2009;62:1006-12.

24. Petticrew $M$, Rehfuess $E$, Noyes J, et al. Synthesizing evidence on complex interventions: how meta-analytical, qualitative, and mixed-method approaches can contribute. J Clin Epidemiol. 2003;66:1230-43.

25. Cowan FM, Pascoe S, Langhaug LF, Mavhu W, Chidiya S, Shabbar J, et al. The Regai Dzive Shiri project: results of a randomized trial of an HIV prevention intervention for Zimbabwean youth. AIDS. 2010;24:2541-52.

26. Stark L, Seff I, Assezenew A, Eoomkham J, Falb K. Ssewamala. Effects of a social empowerment intervention on economic vulnerability for adolescent refugee girls in Ethiopia. J Adolesc Health. 2018;62:S15-20.

27. USAID. Testing a service-delivery model for offering long-acting reversible contraceptive methods to youth in Ethiopia. Study Report, 2017.

28. Ezeanolue EE, Obiefune MC, Yang W, Ezeanolue CO, Pharr J, Osuji A, et al. What do you need to get male partners of pregnant women tested for HIV in resource limited settings? The baby shower cluster randomized trial. AIDS Beh. 2017; 21: 587-96.

29. Ishola AG, Chipps J. The use of mobile phones to deliver acceptance and commitment therapy in the prevention of mother-child HIV transmission in Nigeria. J Telemed Telecare. 2015;21:423-6.
30. Okonofua FE, Coplan P, Collins S, Oronsaye F, Ogunsakin D, Ogonor JT, et al Impact of an intervention to improve treatment-seeking behavior and prevent sexually-transmitted diseases among Nigerian youths. Int J Infect Dis. 2003;7:61-73.

31. Mercy Corps. Improving child and maternal health: Why adolescent girl programming matters. Post-intervention Evidence from Niger, 2015

32. Bass JK, Annan J, Murray SM, Kaysen D, Griffiths S, Cetinoglu T, et al. Controlled trial of psychotherapy for Congolese survivors of sexual violence. N Engl J Med. 2013;368:82-91.

33. O'Callaghan P, McMullen J, Shannon C, Rafferty H, Black A. A randomized controlled trial of trauma-focused cognitive behavioral therapy for sexually exploited, war-affected Congolese girls. J Am Acad Child Adolesc Psychiatry.

34. Panter-Brick C, Dajani R, Eggerman M, Hermosilla S, Sancilio A, Ager A. Insecurity, distress and mental health: experimental and randomized controlled trials of a psychosocial intervention for youth affected by the Syrian crisis. J Child Psychol Psychiatry. 2018;59:523-41.

35. Lange-Nielsen ID, Kolltveit S, Thabet A, Dyregrov A, Pallesen S, Johnsen TB, et al. Short-term effects of a writing intervention among adolescents in Gaza. J Loss Trauma. 2011;17:403-22.

36. Barron I, Abdallah G, Heltne U. Randomized control trial of teaching recovery techniques in rural occupied Palestine: effect on adolescent dissociation. J Aggress Maltreat Trauma. 2016;9:955-73.

37. Punamki R, Peltone K, Diab M, Qouta SR. Psychosocial interventions and emotion regulation among war-affected children: randomized controlled trial effects. Traumatol. 2014;20:241-52.

38. Qouta SR, Palosaari E, Diab M, Punamaki R. Intervention effectiveness among war-affected children: a cluster randomized controlled trial on improving mental health. J Trauma Stress. 2012;25:288-98.

39. Diab M, Peltonen K, Qouta SR, Palosaari E, Punamaki R. Effectiveness of psychosocial intervention enhancing resilience among war-affected children and the moderating role of family factors. Child Abuse Negl. 2015;40:24-35.

40. Kalantari M, Yule W, Dyregrov A, Neshatdoost H, Ahmadi SJ. Efficacy of writing for recovery on traumatic grief symptoms of Afghani refugee bereaved adolescents: a randomized control trial. Omega. 2012;65:139-50.

41. Mon M, Liabsuetrakul T, McNeil EB, Htut K. Mindfulness-integrated reproductive health package for adolescents with parental HIV infection: a group-randomized controlled trial. Vulnerable Child Youth Stud. 2017;12: 147-59.

42. Mon M, Liabsuetrakul T, Htut K. Effectiveness of mindfulness intervention on psychological behaviors among adolescents with parental HIV infection: a group-randomized controlled trial. Asia Pac J Public Health. 2016;28:767-75.

43. Newman SJ, Rocca CH, Zakaras JM, Onono M, Bukusi EA, Grossman D, et al. Does integrating family planning into HIV services improve gender equitable attitudes? Results from a cluster-randomized trial in Nyanza, Kenya. AIDS Beh. 2016;20:1883-92.

44. Bryant RA, Schafer A, Dawson KS, Najuri D, Mulili C, Ndognoi L, et al. Effectiveness of a brief behavioral intervention on psychological distress among women with a history of gender-based violence in urban Kenya: a randomized clinical trial. PLoS Med 2017; 14(8): e1002371. https://doi.org/ https://doi.org/10.1371/journal.pmed.1002371.

45. Dawson KS, Schafer A, Anjuri D, Ndogoni L, Musyoki C, Sijbrandij M. Feasibility trial of a scalable psychological intervention for women affected by urban violence and gender-based violence in Nairobi. BMC Psychiatry. 2016;16:410

46. Baiocchi M, Omondi B, Langat N, Boothroyd DB, Sinclair J, Pavia L, et al. A behavior-based intervention that prevents sexual assault: the results of a matched-pairs, cluster-randomized study in Nairobi. Kenya Prev Sci. 2017;18: 818-27.

47. Puffer E, Green EP, Sikkema KJ, Broverman SA, Ogwang-Odhiambo RA, Pian J. A church-based intervention for families to promote mental health and prevent HIV among adolescents in rural Kenya: results of a randomized trial. J Consult Clin Psychol. 2016;84:511-25.

48. Cohen CR, Grossman D, Onono M, Blat C, Newmann SJ, Burger RL, et al. Integration of family planning services into HIV care clinics: results one year after a cluster randomized controlled trial in Kenya. PLoS One 2017;12(3): e0172992. https://doi.org/https://doi.org/10.1371/journal.pone.0172992.

49. Turan JM, Onono M, Steinfeld RL, Shade S, Owuor K, Washington S, et al. Effects of antenatal care and HIV treatment integration on elements of the PMTCT cascade: results from the SHAIP cluster-randomized controlled trial in Kenya. J Acquir Immune Defic Syndr. 2015;69(5):e172-81. https://doi.org/ 10.1097/QAl.0000000000000678. 
50. Adam MB. Short report: effectiveness trial of community-based I choose lifeAfrica human immunodeficiency virus prevention program in Kenya. Am J Trop Med Hyg. 2014;91:645-8.

51. Grossman D, Onono M, Newman SJ, Blat C, Bukusi EA, Shade SB, et al. Integration of family planning services into HIV care treatment in Kenya: a cluster-randomized trial. AIDS. 2013;27:S77-85.

52. Penfold S, Manzi F, Mukumbo E, Temu S, Jaribu J, Shamba D, et al. Effect of home-based counseling on newborn care practices in southern Tanzania one year after implementation: a cluster-randomized controlled trial. BMC Ped. 2014;14:187.

53. Magoma M, Requejo J, Campbell O, Cousens S, Merialdi M, Filippi V. The effectiveness of birth plans in increasing use of skilled care at delivery and postnatal care in rural Tanzania: a cluster randomized trial. Tropical Med Int Health. 2013;18:434-43.

54. Ross DA, Changalucha J, Obasi A, Todd J, Plummer ML, Cleophas-Mazige B, et al. Biological and behavioural impact of an adolescent sexual health intervention in Tanzania: a community randomized trial. AIDS. 2007;21: 1943-55.

55. Jordans M, Komproe $I H$, Wietse AT, Kohrt BA, Luitel NP, Macy RD, et al Evaluation of a classroom-based psychosocial intervention in conflictaffected Nepal: a cluster-randomized controlled trial. J Child Psychol Psychiatr. 2010; 51: 818-26.

56. Ssewamala F, Ismayilova L, McKay M, Sperber E, Bannon W, Alicea S. Gender and the effects of an economic empowerment program on attitudes towards sexual risk-taking among AIDS-orphaned adolescent youth in Uganda. J Adolesc Health. 2010;46:372-8.

57. Bolton P, Bass J, Betancourt T, Speelman L, Onyango G, Clougherty KF, et al. Interventions for depression symptoms among adolescent survivors of war and displacement in northern Uganda. JAMA. 2017;298:519-27.

58. Devries KM, Knight L, Allen E, Parkes J, Kyegombe N, Naker D. Does the good schools toolkit reduce physical, sexual and emotional violence, and injuries, in girls and boys equally?: a cluster-randomized controlled trial. Prev Sci. 2017;18:839-53.

59. Atwood K, Kennedy SB, Shamblen S, Tegli J, Garber S, Fahnbulleh PW, et al. Impact of a school-based HIV prevention program in post-conflict Liberia. AIDS Educ Prev. 2012;24:68-77.

60. Hossain M, Zimmerman C, Kiss L, Abramsky T, Kone D, Bakayoko-Topolska M. Working with men to prevent intimate partner violence in a conflictaffected setting: a pilot cluster randomized controlled trial in rural cote d'Ivoire. BMC Pub Health. 2014;14:339.

61. Gupta J, Falb KL, Lehman H, Kpbebo D, Xuan Z, Hossain M. Gender norms and economic empowerment intervention to reduce intimate partner violence against women in rural cote d'lvoire: a randomized controlled pilot study. BMC Int Health Hum Rights. 2013;13:46 http://www.biomedcentral. com/1472-698X/13/46

62. Villaruel AM, Zhou Y, Gallegos EC, Ronis DL. Examining long-term effects of Cuidate- a sexual risk reduction program in Mexican youth. Rev Panam Salud Publica. 2010;27:345-51.

63. Kaljee LM, Genberg B, Riel R, Cole M, Tho L, Thoa $L$, et al. Effectiveness of a theory-based risk reduction HIV prevention program for rural Vietnamese adolescents. AIDS Educ Prev. 2005;17:185-99.

64. Leventhal KS, DeMaria LM, Gillham JE, Andrew G, Peabody J, Leventhal SM. A psychosocial resilience curriculum provides the "missing piece" to boost adolescent physical health: a randomized controlled trial of girls first in India. Soc Sci Med. 2016;161:37-46.

65. Leventhal KS, Gillham J, DeMaria L, Andrew G, Peabody J, Leventhal S. Building psychosocial assets and wellbeing among adolescent girls: a randomized controlled trial. J Adolesc. 2015;45:284-95.

66. Raj A, Ghule M, Ritter J, Battala M, Gajanan V, Nair S, et al. Cluster randomized controlled trial evaluation of a gender equity and family planning intervention for married men and couples in rural India. PLOS One. 2016; 11(5). DOl:https://doi.org/10.1371/journal.pone.0153190.

67. Jewkes R, Nduna M, Levin J, Jama N, Dunkle K, Puren A, et al. Impact of stepping stones on incidence of HIV and HSV-2 and sexual behavior in rural South Africa: cluster randomized controlled trial. Br Med J. 2008;337:a506.

68. Taylor M, Jinabhai C, Dlamini S, Sathiparsad R, Eggers MS, DeVries H. Effects of a teenage pregnancy prevention program in KwaZulu-Natal. South Africa Health Care Women Int. 2014;35:845-58.

69. Matthews C, Eggers SM, Townsend L, Aaro LE, de Vries PJ, Mason-Jones AJ, et al. Effect of PREPARE, a multi-component, school-based HIV and intimate partner violence (IPV) prevention program on adolescent sexual risk behavior and IPV: cluster randomized controlled trial. AIDS Beh. 2016;20: 1821-40.

70. Jones DL, Peltzer K, Villar-Loubet O, Shikwane E, Cook R, Vamos S, et al. Reducing the risk of HIV infection during pregnancy among south African women: a randomized controlled trial. AIDS Care. 2013;25:702-9.

71. Mott MacDonald Evaluation Team. Adolescent girls empowerment programme, Zambia. End Term Evaluation Report, 2017.

72. Vance $G$, Janowitz B, Chen M, Boyer B, Kasonde P, Asare G, et al. Integrating family planning messages into immunization services: a cluster randomized trial in Ghana and Zambia. Health Policy Plan. 2014;29:359-66.

73. Rokicki S, Cohen J, Salomon JA, Fink G. Impact of a text-messaging program on adolescent reproductive health: a cluster-randomized trial in Ghana. Am J Pub Health. 2017;107:298-305.

74. Aninanya GA, Debpuur CY, Awine T, Williams JE, Hodgson A, Howard N. Effects of an adolescent sexual and reproductive health intervention on health service usage by young people in northern Ghana: a community randomized trial. PLoS One. 2015;10(4):e0125267. https://doi.org/10.1371/ journal.pone.0125267.

75. Carlson CE, Chen J, Chang M, Batsukh A, Toivgoo A, Riedel M, et al. Reducing intimate and paying partner violence against women who exchange sex in Mongolia: results from a randomized clinical trial. J Interpers Violence. 2012;27:1911-31.

76. Khan MN, Dherani M, Chiumento A, Atif N, Bristow K, Sikander S, et al. Evaluating feasibility and acceptability of a local psycho-educational intervention for pregnant women with common mental problems affected by armed conflict in swat, Pakistan: a parallel randomized controlled feasibility trial. Int J Soc Psychiatry. 2017;63:724-35.

77. Bhutta ZA, Soofi S, Cousens S, Mohammad S, Memon Z, Ali I, et al. Improvement of perinatal and newborn care in rural Pakistan through community-based strategies: a cluster-randomized effectiveness trial. Lancet. 2011;377:402-12.

78. Bastani F, Hidarnia A, Montgomery KS, Aguilar-Vafaei ME, Kazemnejad A. Does relaxation education in anxious Primigravid Iranian women influence adverse pregnancy outcomes? A randomized controlled trial. J Perinat Neonat Nurs. 2016;20:138-46.

79. Berger R, Gelkopf M, Heineberg Y. A teacher-delivered intervention for adolescents exposed to ongoing and intense traumatic war-related stress: a quasi-randomized controlled tiral. J Adolesc Health. 2012;51:453-61.

80. Chorpita BF, Daleiden EL. Mapping evidence-based treatments for children and adolescents: application of the distillation and matching model to 615 treatments from 322 randomized trials. J Consult Clin Psychol. 2009;77:56679.

81. Brown FL, de Graaf AM, Annan J, Betancourt T. Annual research review: breaking cycles of violence- a systematic review and common practice elements analysis of psychosocial interventions for children and youth affected by conflict. J Child Psychol Psychiatry. 2016. https://doi.org/10.1111/ jcpp.12671.

82. Jackson N, Waters E. Criteria for the systematic review of health promotion and public health interventions. Health Promot Int. 2005;20:367-74.

83. Sing NH, Smith J, Aryasinghe S, Khosla R, Say L, Blanchet K. Evaluating effectiveness of sexual and reproductive health services during humanitarian crisis: a systematic review. PLoS One 2018; 13(7): e0199300. https://doi.org/https://doi.org/10.1371/journal.pone.01.

84. Weisz JR, Ng MY, Ugueto AM, Jensen-Doss A, Marchette LSK, Weersing VR et al. What five decades of research tells us about the effects of youth psychological therapy: a multilevel meta-analysis and implications for science and practice. Am Psychol. 2017;2:79-117.

85. Barker G, Ricardo C, Nascimento M. Engaging men and boys in changing gender-based inequity in health: evidence from programme interventions. Geneva: World Health Organization; 2007.

86. Comrie-Thomson L, Tokhi M, Ampt F, Portela A, Chersich M, Khanna R, et al. Challenging gender inequity through male involvement in maternal and newborn health: critical assessment of an emerging evidence base. Cult Health Sex. 2015;17:S177-89.

87. World Health Organization (WHO). WHO recommendations on health promotion interventions for maternal and newborn health 2015. Geneva: World Health Organization; 2015.

\section{Publisher's Note}

Springer Nature remains neutral with regard to jurisdictional claims in published maps and institutional affiliations. 